\title{
Experimental and Mathematical Investigations of Dicalcium Phosphate: Moisture Sorption Isotherms
}

\author{
Jmai Sana* and Bagane Mohamed
}

Tunis Governorate, Tunisia

\begin{abstract}
The aim of this work was to determine desorption isotherms of Tunisian dicalcium phosphate. The equilibrium moisture contents of dicalcium phosphate were measured using the gravimetric method at four temperatures $\left(50,60,70\right.$ and $\left.80^{\circ} \mathrm{C}\right)$ and in wide range water activity (0.021-0.989). Desorption data of dicalcium phosphate were best fitted by the Guggenhein, Anderson and de Boer model at four temperatures.
\end{abstract}

Keywords: Dicalcium phosphate; Moisture; Sorption isotherms

\section{Introduction}

The parameters necessary for dryers design and for carrying out the process of drying under optimum conditions can be found in both experimental and theoretical ways. The latter seems to be more convenient and economical in the present state of computational techniques.

A theoretical treatment, however, needs the knowledge of the mechanism of moisture transfer in a dried body together with an appropriate mathematical description that appears to be still a problem requiring solution.

Lewis [1] first published the paper dealing with moisture transfer during drying of solid materials and proposing also a simple mathematical description. Since then hundreds of various papers have been issued bringing a great number of different, very often partly contradictory views and opinions. The authors rarely give comprehensive, critical review of state of the art thereby making full understanding of the problem more difficult. Dicalcium phosphate, yet named monoacid precipitate [2], is known in the anhydrous state $\mathrm{CaHPO}_{4}$ (monétite) and dihydrate state $\mathrm{CaHPO}_{4}, 2 \mathrm{H}_{2} \mathrm{O}$ (brushite). This compound exists in superphosphate and complex fertilizers with nitrogen, phosphorus and potassium (NPK) basis. In the pure state, dicalcium phosphate is used in the preparation of food for livestock and toothpastes.

Brushite $\mathrm{CaHPO}_{4}, 2 \mathrm{H}_{2} \mathrm{o}$, the only well-established hydrate of calcium hydrogen phosphate, has applications in the fertilizer and animal-food industries [3] in water decontamination [4].

Monetite is the anhydrous form of brushite and can be obtained via heat treatment of brushite or by the modification of the precipitation conditions [5].

A sound knowledge of sorption isotherms is essential for drying processes. The final moisture content of dried product and the energy required for drying can be estimated from sorption isotherms. Due to the complexity of the product, there is no one model that fits all the cases well. As a consequence, many models have been proposed in the literature, and it is interesting to check how well some of them fit to experimental data [6].

Dicalcium phosphate, which is composed from 40 to $45 \%$ of $\mathrm{P}_{2} \mathrm{O}_{5}$ and 20 to $25 \%$ calcium, is characterized by a ratio of $\mathrm{Ca} / \mathrm{P}=1.3$, is made in the chemical group of Gabes at a rate of $4.8 \mathrm{t} / \mathrm{h}$ and a mass composition of $41.7 \%$.
We were interested in determining the desorption isotherms of water vapor on dicalcium and modeling these isotherms which allows us a better understanding and a good characterization of the industrial product and therefore to optimize the phosphate operating parameters of the industrial drier.

\section{Smoothing Sorption Isotherms}

Given the complex multi-component product structure, sorption isotherms are only representative of the tested material [7]. Given the complexity of the phenomena occurring during the desorption of water (mass transfer and heat), various simplified mathematical models have been proposed for predicting the dependence of the equilibrium water content $\left(\mathrm{X}_{\mathrm{eq}}\right)$ and water activity (aw) (and typically $(\mathrm{T})$ ). These isotherm models can be theoretical, semi theoretical or empirical. The choice of suitable model depends on a number of factors. We focus on those that describe mathematically the best experimental sorption curves for practical drying applications dicalcium phosphate.

\section{Modelling of Sorption Isotherms}

The dry basis moisture contents were used for the modelling. The experimental sorption isotherms data were fitted using ....mathematical models as shown in Table 1 . To evaluate the ability of each model to fit the experimental data, the standard error (ES) and the coefficient of correlation ( $r$ ) between the experimental and the predicted data were determined using the following equations:

$$
\begin{gathered}
E S=\sqrt{\sum_{j=1}^{N} \frac{\left(X_{j c a l}-X_{j \exp }\right)^{2}}{N-n p}} \\
R=\sqrt{1-\frac{\sum_{j=1}^{N}\left(X_{j c a l}-X_{j \exp }\right)^{2}}{\sum_{j=1}^{N}\left(X_{m}-X_{j \exp }\right)^{2}}}
\end{gathered}
$$

*Corresonding author: Jmai Sana, Tunis Governorate, Tunisia, E-mail: sanajmai1@gmail.com

Received November 20, 2014; Accepted January 08, 2015; Published January 15,2015

Citation: Sana J, Mohamed B (2015) Experimental and Mathematical Investigations of Dicalcium Phosphate: Moisture Sorption Isotherms. J Food Process Technol 6 418. doi:10.4172/2157-7110.1000418

Copyright: ( $) 2015$ Sana J, et al. This is an open-access article distributed unde the terms of the Creative Commons Attribution License, which permits unrestricted use, distribution, and reproduction in any medium, provided the original author and source are credited. 
Citation: Sana J, Mohamed B (2015) Experimental and Mathematical Investigations of Dicalcium Phosphate: Moisture Sorption Isotherms. J Food Process Technol 6: 418. doi:10.4172/2157-7110.1000418

Page 2 of 4

\begin{tabular}{|c|c|c|}
\hline Modèle & Equation du modèle & References \\
\hline BET & $\mathrm{Xeq}=\frac{A X m a w}{(1-a w)(1+(A-1) a w)}$ & (Brunauer, 1938) \\
\hline BET modifié (1996) & $\mathrm{X}_{\mathrm{eq}}=\frac{A}{1-B \cdot a w}$ & (Brunauer, 1938) \\
\hline Smith & $\mathrm{X}_{\mathrm{eq}}=\mathrm{A}-\mathrm{B} \cdot \ln \left(1-a_{w}\right)$ & (Smith, 1947) \\
\hline Iglesias et chirife & $\mathrm{X}_{\mathrm{eq}}=\mathrm{A}+\mathrm{B} \cdot \frac{a w}{1-a w}$ & (Iglesias, 1981) \\
\hline White et Eiring & $\mathrm{X}_{\mathrm{eq}}=\frac{1}{A+B \cdot a w}$ & (Castillo, 2003) \\
\hline Peleg & $\mathrm{X}_{\mathrm{eq}}=\mathrm{A} \cdot(a w)^{B}+C \cdot(a w)^{D}$ & (Peleg, 1993) \\
\hline $\begin{array}{l}\text { Guggenhein, Anderson } \\
\text { and Boer }\end{array}$ & $\mathrm{X}_{\mathrm{eq}}=\frac{X_{m} \cdot A \cdot B \cdot a w}{(1-B \cdot a w)(1-B \cdot a w+A \cdot B \cdot a w)}$ & (Van Der Berg, 1981) \\
\hline Oswin & $\mathrm{X}_{\mathrm{eq}}=\mathrm{A} \cdot\left(\frac{a w}{1-a w}\right)^{B}$ & (Oswin, 1946) \\
\hline Adam & $\mathrm{X}_{\mathrm{eq}}=\mathrm{A}+\mathrm{B} \cdot \mathrm{aw}+\mathrm{C} \cdot \mathrm{aw}^{2}+\mathrm{D} \cdot \mathrm{aw}^{3}$ & (Chirife, 1978) \\
\hline Caurie & $\mathrm{X}_{\mathrm{eq}}=\exp \left(A+B \cdot a_{w}\right)$ & (Castillo, 2003) \\
\hline Freundlich & $\mathrm{X}_{\mathrm{eq}}=\mathrm{A} \cdot \mathrm{a}_{\mathrm{w}}{ }^{\mathrm{B}}$ & (Freundlich, 1909) \\
\hline Halsey & $\mathrm{X}_{\mathrm{eq}}=\left(-\frac{A}{\ln (a w)}\right)^{(1 / B)}$ & (Halsey, 1948) \\
\hline Langmuir & $\mathrm{X}_{\mathrm{eq}}=\mathrm{X}_{\mathrm{m}} \frac{A \cdot a w}{(1+C \cdot a w)}$ & (Langmuir, 1916) \\
\hline
\end{tabular}

methods are indirect methods. It is noted that in general, a direct method is indirect method accuracy.

During the work we opted for the gravimetric method.

\section{Device experimental}

The assembly diagram is shown in Figure 1.

It consists essential of:

- An air compressor; Two silica gel columns to dehumidify the air (2);

- Two Bubblers (3) which provides air saturated with water vapor at the temperature set by the thermostat balance;

- Five thermostated bath (4);

- A main tube (5) dipping into a water bath (6) to keep moist air at a constant temperature; drift tube by four tubes each opening into a desorption stage (7) having a fixed temperature;

Using this experimental device was able to conduct further experiments in parallel desorption temperatures: 50, 60, 70 and $80^{\circ} \mathrm{C}$. The risk of condensation was avoided by using the heaters of each head surrounding the sorption column.

The amount of desorbed water vapour is measured from the change in mass of different samples using a Sartorius balance with an accuracy of 10-4.

Equilibrium is reached when there is almost no variation of the mass (1\%).

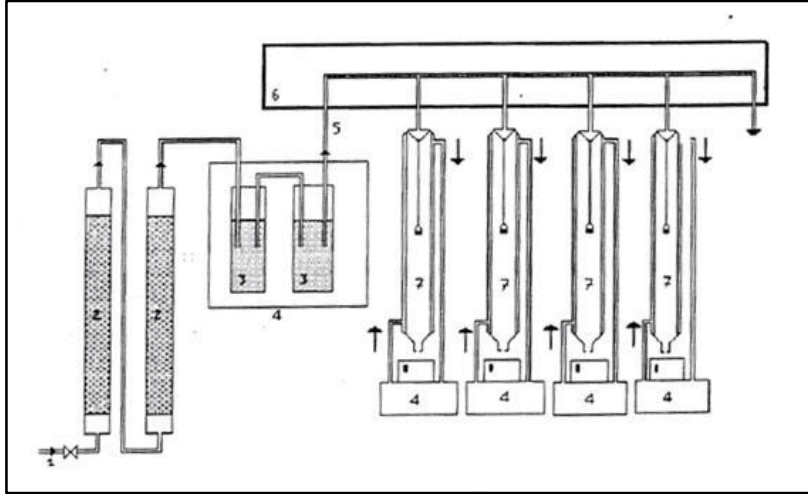

Figure 1: The Schema of the installation. of the water contents in the case of reduced kinetic drying and water content at equilibrium in the case of the sorption isotherms.

$\mathrm{N}$ : the number of experimental points.

$\mathrm{np}$ : the number of model constants.

The models are compared using the standard error (SE) and the correlation coefficient $(r)$ to the different heating powers and temperatures studied taking into account the graphs. In what follows, we include the different models used for smoothing of the experimental results.

\section{Experimental Study}

The amount of adsorbed molecules is taken either by direct methods or by indirect methods. Gravimetric and volumetric methods are direct methods. In a volumetric method, the adsorbed amount is expressed as the volume per unit area or per unit mass of the sample powder. Furthermore, IR and UV spectroscopy in most other instrumental

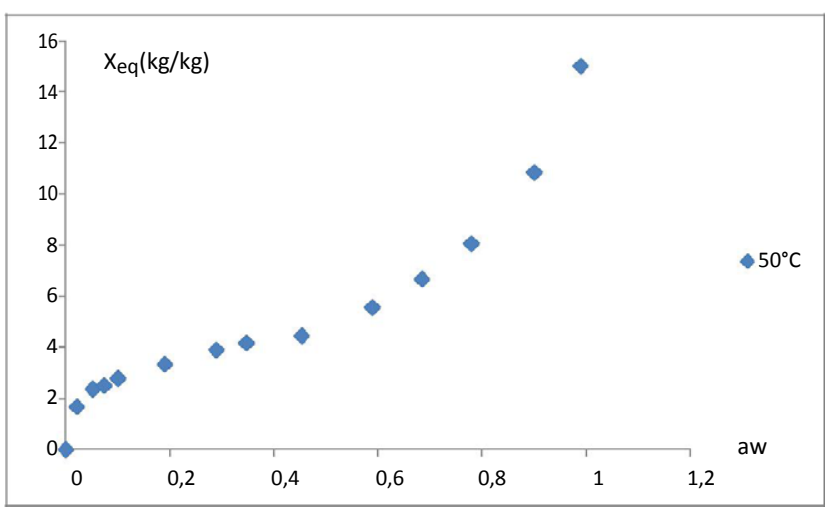

Figure 2: Desorption isotherme $\mathrm{T}=50^{\circ} \mathrm{C}$. 
Citation: Sana J, Mohamed B (2015) Experimental and Mathematical Investigations of Dicalcium Phosphate: Moisture Sorption Isotherms. J Food Process Technol 6: 418. doi:10.4172/2157-7110.1000418

Page 3 of 4

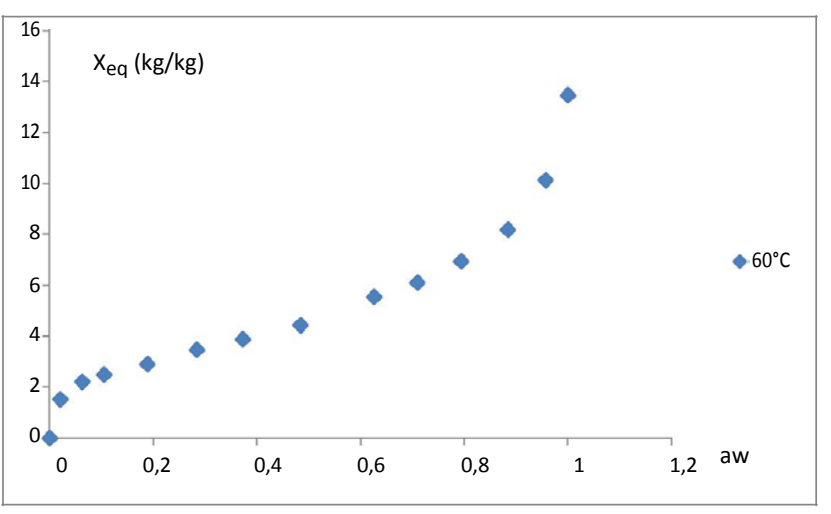

Figure 3: Desorption isotherm $\mathrm{T}=60^{\circ} \mathrm{C}$.

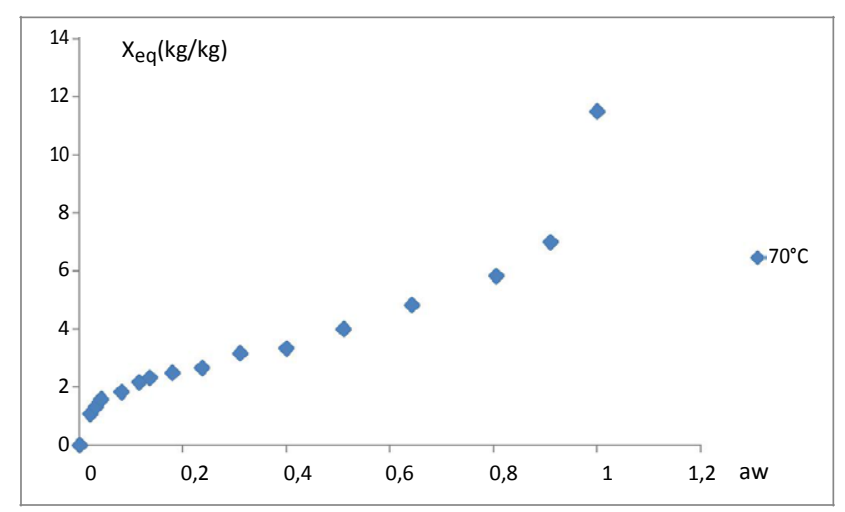

Figure 4: Desorption isotherm $\mathrm{T}=70^{\circ} \mathrm{C}$.

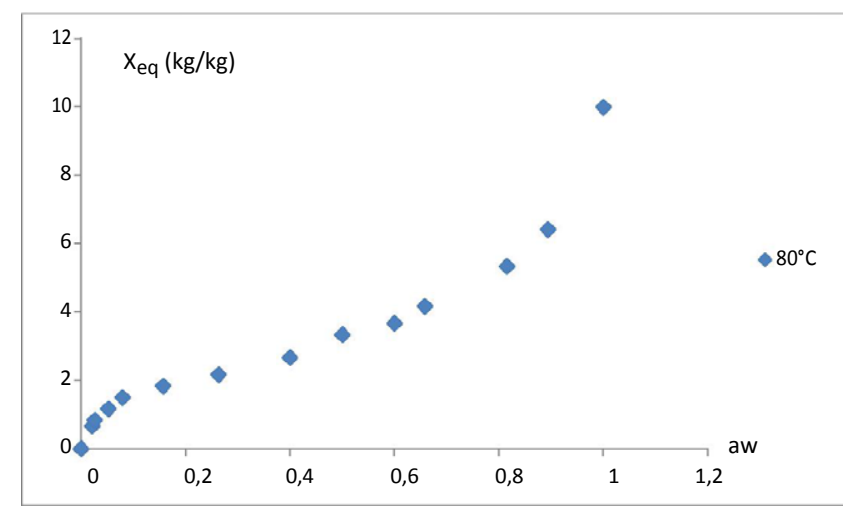

Figure 5: Desorption isotherm $\mathrm{T}=80^{\circ} \mathrm{C}$.

\section{Modelling Results}

Desorption isotherms of water vapour at the temperatures 50, 60, 70 and $80^{\circ} \mathrm{C}$ on dicalcium phosphate are brought in Figures 2, 3, 4 and 5.

According to their shape, these isotherms are Type II on BET classification indicating that dicalcium phosphate is macro-porous (pore diameter $>200 \mathrm{~A}^{\circ}$ ). Further interaction adsorbate-adsorbent is larger than the interaction adsorbate-adsorbate.

\begin{tabular}{|c|c|c|c|c|}
\hline Modèle & $\mathbf{T}=\mathbf{5 0}$ & $T=60$ & $T=70$ & $T=80$ \\
\hline \multicolumn{5}{|l|}{ Halsey $X_{e q}=\left(-\frac{A}{\ln (a w)}\right)^{(1 / 3)}$} \\
\hline A & 186.705 & 57.728 & 17.572 & 6.793 \\
\hline B & 3.5039 & 3.006 & 2.582 & 2.131 \\
\hline r & 0.959 & 0.977 & 0.97 & 0.974 \\
\hline SE & 1.133 & 0.586 & 0.435 & 0.385 \\
\hline \multicolumn{5}{|c|}{ White and Eiring: $X_{e q}=\frac{1}{A+B a w}$} \\
\hline A & 0.363 & 0.389 & 0.4863 & 0.626 \\
\hline B & -0.301 & -0.304 & -0.384 & -0.533 \\
\hline$r$ & 0.9937 & 0.985 & 0.957 & 0.961 \\
\hline SE & 0.449 & 0.461 & 0.521 & 0.526 \\
\hline \multicolumn{5}{|c|}{ BET $X_{e q}=\frac{A X m a w}{(1-a w)(1+(A-1) a w)}$} \\
\hline A & 64.489 & 61.529 & 35.038 & 36.144 \\
\hline $\mathrm{Xm}$ & 2.839 & 2.563 & 2.303 & 1.747 \\
\hline $\mathrm{R}$ & 0.997 & 0.998 & 0.989 & 0.991 \\
\hline SE & 0.053 & 0.039 & 0.073 & 0.069 \\
\hline \multicolumn{5}{|c|}{ BET modifié $X_{e q}=\frac{A}{1-B \cdot a w}$} \\
\hline A & 2.748 & 2.57 & 2.055 & 1.597 \\
\hline B & 0.827 & 0.783 & 0.791 & 0.852 \\
\hline r & 0.993 & 0.985 & 0.957 & 0.961 \\
\hline SE & 0.449 & 0.461 & 0.521 & 0.526 \\
\hline \multicolumn{5}{|c|}{ Smith $X_{e q}=A-B \cdot(\ln (1-a w))$} \\
\hline A & 2.68 & 2.386 & 1.821 & 1.196 \\
\hline B & 2.984 & 2.669 & 2.397 & 2.492 \\
\hline r & 0.983 & 0.985 & 0.969 & 0.984 \\
\hline SE & 0.723 & 0.467 & 0.445 & 0.334 \\
\hline \multicolumn{5}{|c|}{ Iglesias et chirife $X_{e q}=A+B \cdot \frac{a w}{1-a w}$} \\
\hline A & 4.4389 & 3.663 & 2.368 & 1.797 \\
\hline B & 0.125 & 0.347 & 0.548 & 0.652 \\
\hline r & 0.801 & 0.839 & 0.862 & 0.897 \\
\hline SE & 2.403 & 1.495 & 0.9200 & 0.842 \\
\hline \multicolumn{5}{|c|}{ Caurie $X_{e q}=\exp \left(A+B \cdot a_{w}\right)$} \\
\hline$A$ & 0.607 & 0.681 & 0.541 & 0.166 \\
\hline B & 2.035 & 1.651 & 1.557 & 1.892 \\
\hline r & 0.985 & 0.992 & 0.984 & 0.989 \\
\hline SE & 0.683 & 0.801 & 0.315 & 0.278 \\
\hline \multicolumn{5}{|l|}{ Freundlich $X_{e q}=A \cdot a_{w}{ }^{B}$} \\
\hline A & 12.168 & 8.714 & 6.493 & 6.022 \\
\hline B & 1.012 & 0.703 & 0.547 & 0.708 \\
\hline$r$ & 0.916 & 0.949 & 0.974 & 0.969 \\
\hline SE & 1.609 & 0.861 & 0.409 & 0.469 \\
\hline \multicolumn{5}{|c|}{ Langmuir $X_{e q}=X_{m} \frac{A . a w}{(1+C \cdot a w)}$} \\
\hline $\mathrm{Xm}$ & 3.686 & 3.194 & 2.94 & 2.485 \\
\hline A & 34.533 & 40.093 & 26.143 & 18.194 \\
\hline$r$ & 0.980 & 0.987 & 0.988 & 0.997 \\
\hline SE & 0.138 & 0.110 & 0.089 & 0.039 \\
\hline \multicolumn{5}{|l|}{ Oswin $X_{e q}=A \cdot\left(\frac{a w}{1-a w}\right)^{B}$} \\
\hline A & 5.266 & 4.625 & 3.825 & 3.19 \\
\hline$B$ & 0.244 & 0.265 & 0.277 & 0.338 \\
\hline$r$ & 0.982 & 0.996 & 0.995 & 0.997 \\
\hline
\end{tabular}


Citation: Sana J, Mohamed B (2015) Experimental and Mathematical Investigations of Dicalcium Phosphate: Moisture Sorption Isotherms. J Food Process Technol 6: 418. doi:10.4172/2157-7110.1000418

Page 4 of 4

\begin{tabular}{|c|c|c|c|c|}
\hline ES & 0.741 & 0.244 & 0.169 & 0.129 \\
\hline \multicolumn{5}{|c|}{ Adam $X_{e q}=A+B \cdot a w+C \cdot a w^{2}+D \cdot a w^{3}$} \\
\hline A & 1.447 & 1.399 & 1.084 & 0.657 \\
\hline B & 16.292 & 16.759 & 9.84 & 8.985 \\
\hline $\mathrm{C}$ & -36.095 & -19.568 & -13.736 & -13.93 \\
\hline D & 33.551 & 17.436 & 11.072 & 12.36 \\
\hline r & 0.998 & 0.998 & 0.997 & 0.997 \\
\hline ES & 0.230 & 0.177 & 0.13 & 0.14 \\
\hline \multicolumn{5}{|c|}{ Guggenhein $X_{e q}=\frac{X_{m} \cdot A \cdot B \cdot a w}{(1-B \cdot a w)(1-B \cdot a w+A \cdot B \cdot a w)}$} \\
\hline $\mathrm{Xm}$ & 2.990 & 2.905 & 2.644 & 2.087 \\
\hline A & 69.545 & 57.791 & 40.283 & 28.761 \\
\hline B & 0.809 & 0.744 & 0.692 & 0.79 \\
\hline $\mathrm{R}$ & 0.999 & 0.998 & 0.998 & 0.998 \\
\hline ES & 0.105 & 0.137 & 0.113 & 0.092 \\
\hline \multicolumn{5}{|c|}{ Peleg $X_{e q}=A \cdot(a w)^{B}+C \cdot(a w)^{D}$} \\
\hline A & 9.649 & 5.69 & 3.499 & 3.87 \\
\hline B & 5.223 & 4.42 & 3.197 & 0.414 \\
\hline C & 5.782 & 5.371 & 4.519 & 4.09 \\
\hline D & 0.319 & 0.335 & 0.349 & 3.817 \\
\hline$r$ & 0.999 & 0.998 & 0.998 & 0.998 \\
\hline ES & 0.161 & 0.162 & 0.092 & 0.109 \\
\hline
\end{tabular}

Table 2: Estimated parameters and fitting criteria of the models applied to experimental.

Furthermore, for the same relative humidity, the amount of desorbed water vapour increases with decreasing temperature which is consistent with the exothermic nature of the desorption.

\section{Smoothing Experimental Desorption Curves}

The choice of the mathematical model is based on statistical parameters for the comparison of different models. Indeed, the greatest

value of the correlation coefficient $(\mathrm{r})$ and the lowest values of the standard error (SE) are the criteria that justify the choice of the most appropriate model for smoothing the experimental sorption curves. The Table 2 include constants and statistical parameters thirteen models used to smooth the desorption isotherms dicalcium phosphate. The results show that the model gives the best smoothing Guggenhein, Anderson and de Boer isotherms desorption temperature in the range of $50-80^{\circ} \mathrm{C}$.

\section{Conclusion}

The desorption isotherms of dicalcium phosphate were determined at four temperatures $\left(50,60,70\right.$ and $\left.80^{\circ} \mathrm{C}\right)$ using the gravimetric method. The desorption isotherms of calcium phosphate have a sigmoid form and display the type II on BET classification.

Guggenhein, Anderson and de Boer data of desorption isotherms in the range of investigated temperatures (from 50 to $80^{\circ} \mathrm{C}$ ) and water activities (from 0.021 to 0.989 ).

\section{References}

1. Lewis W (1921) The rate of drying of solid materials. Journal of industrial and enginnering chemistry $13: 427-432$

2. Hafid, D (1986) synthese mecanochimique et reactivite du phosphate bicalcique.

3. Smith DW (1962) The Structure of Brwhite, CaHP0, 2H20. J. Chem. Soc. 14141420.

4. Adnane El Hamidi SA (2012) Kinetics and Isotherm Studies of Copper Removal by Brushite Calcium Phosphate: Linear and Non-Linear Regression Comparison. Journal of Chemistry 9: 1532-1542.

5. Camaa BG (2013) A novel method of forming micro- and macroporous. Journa of Materials Chemistry 1: 958-969.

6. Figen Kaymak-Ertekin MS (2001) Moisture sorption isotherm characteristics of peppers. Journal of food engineering 47: 225-231.

7. Dumoulin EBJD (2004) Activité de l'eau, teneur en eau des produits alimentaires: isothermes de. cahier scientifique. 